Mr Miroslav Elezović, pukovnik, dipl. inž. Tehnički opitni centar,
Beograd,

dr Dragan Đorđević, pukovnik, dipl. inž. Vojna akademija, Beograd
OTPORNOST ELEKTRONSKE OPREME NA TRANZIJENTNE POREMEĆAJE U MREŽI ZA NAPAJANJE

UDC: $621.316: 621.38$

Rezime:

Ispitivanje imunosti elektronske opreme na tranzijentne poremećaje u mreži napajanja obuhvata ispitivanje imunosti na elektrostatičko pražnjenje, brze tranzijente - rafale, naponske udare i propade, kratkotrajne prekide $i$ varijacije napona napajanja. U ovom radu izvršena je teorijska analiza izvora, mehanizam nastajanja i posledica brzih tranzijenata - rafala, kao i eksperimentalna provera ispitivanja imunosti elektronske opreme na brze tranzijente-rafale.

Ključne reči: informaciona tehnologija, elektronska oprema, imunost, brzi tranzijent.

\title{
IMMUNITY ON TRANSIENT DISTURBANCES IN MAIN SUPPLY OF ELECTRONIC EQUIPMENTS
}

Summary:

Testing immunity on transient disturbances in main supply of information electronic equipments includes Hectrostatic discharge immunity test, Electrical fast transient/burst immunity test, Surge immunity test and Voltage dips, Short interruptions and Voltage variations immunity tests. In this paper we performed theoretical analysis of the source, appearance mechanism and consequence of electrical fast transient/burst, and experimental work for Electrical fast transient/burst immunity test of electronic equipments.

Key words: information technology, immunity, fast transient.

\section{Uvod}

Tranzijentni prenaponi u sistemima za napajanje nastaju usled dovođenja energije u sistem za napajanje. U principu, postoje dve vrste izvora: prirodni, kao što su atmosfersko i elektrostatičko pražnjenje, ili pojave koje uzrokuje čovek, kao što su komutacione pojave (prekidački tranzijenti) i naponska pražnjenja usled neispravnosti ili greške.

Linije za napajanje, za razliku od linija za prenos podataka, mogu generisati sopstvene tranzijente, koji se dodaju na ubačene tranzijente. Linije za prenos po- dataka, međutim, samo su objekat na koji se ispolja vaju uticaji okoline.

Radni naponi i tolerancija prenapona komponenti za obradu signala u ovim sistemima za prenos podataka generalno su mnogo niži nego oni kod komponenti sistema za napajanje. Prema tome, šteta (ne računajući probleme prestanka rada) verovatnije će nastati na linijama za prenos podataka nego na komponentama sistema za napajanje, pri istoj izloženosti ubačenim tranzijentima.

Ove pojave uzrokuju kratkotrajne naponske impulse visoke amplitude (reda nanosekunde ili mikrosekunde), dovoljne da 
poremete rad elektronskih kola, a u nekim slučajevima imaju dovoljno energije da oštete ili unište pojedine komponente kola.

U bilo kom okruženju elektronska oprema je podložna gubitku podataka, padu sistema, čak i oštećenjima i uništenju od strane naponskih tranzijenata, kao rezultat odsustva ili pogrešne upotrebe zaštitne opreme. Slič no tome, programabilni logički kontroleri, poluprovodnički kontroleri motora, drajveri za promenu brzina i komponente za komunikaciju mogu biti oštećeni ovim tranzijentima.

Imunost (otpornost) opreme na neke izvore tranzijentnih pojava, koji su prisutni u elektromagnetskom okruženju elektronske opreme, nazivaju se elektromagnetska kompatibilnost (EMC). U ovom radu analiziran je način ispitivanja imunosti uređaja informacione tehnologije na brze tranzijente (rafale) u skladu sa standardom koji definiše IEC (EN) 6100-4-4 (Electrical fast transient/burst immunity test). Kod nas nije obavezna njegova primena, ali se očekuje ubrzana harmonizacija JUS standarda sa standardima EU, standardima EN.

Šte ta na uređajima može biti trenutna, kada tranzijentni napon izazove pre- gorevanje poluprovodničkih komponenata zbog energije tranzijenta ili latentna, kada su izolacija ili komponente ozbiljno podvrgnute opterećenju jednog ili nekoliko tranzijenata, ali ne do tačke neposrednog otkaza. Kasnije, tranzijent ili drugi stres koji u normalnim uslovima ne bi prouzrokovao probleme deluje na oslabljenu izolaciju ili komponente, prouzrokujući neispravnost bez nekog vidljivog razloga.

\section{Brzi tranzijenti}

Tranzijentni naponi, prouzrokovani u uređajima, potiču iz osnovne prirode naizmenične struje. Nagla promena jačine struje u električnom kolu generisaće tranzijentni napon zahvaljujući uskladištenoj energiji koja se nalazi u svim induktansama (L) i kapacitansama (C) u kolu. Veličina i trajanje tranzijenta zavisi od vrednosti L i $\mathrm{C}$ i primenjenog talasnog oblika.

Isključivanje induktivnih kola (preko releja i kontaktora) može generisati rafal visokofrekventnih impulsa, što se vidi na slici 1 .

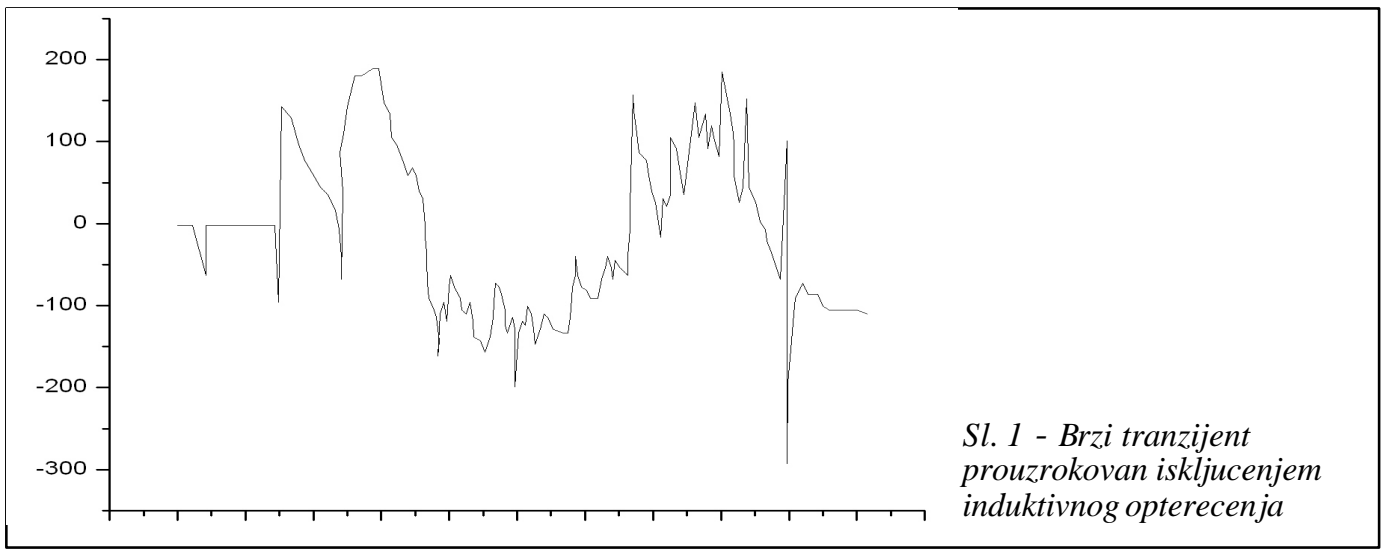


Jedan od glavnih uzroka oscilatornih tranzijenata je kapacitivno prekidanje, čiji je talasni oblik prikazan na slici 2. Tipični kapacitivno-prekidački tranzijent može da dostigne i do $134 \%$ nominalnog napona kondenzatora.

Ciklični motori, kao što su klimatizeri i liftovi, često prouzrokuju brze električne tranzijente, koji su sposobni da proizvedu pikove napona i do $1 \mathrm{kV}$. Rad ručnih zavarivača i startera motora može prouzrokovati tranzijente reda do $3 \mathrm{kV}$.

Uključivanje i isključivanje električnih startera motora ili upotreba lučnih zavariva- ča i upaljača peći može indukovati ove impulse. Kada idu kroz provodnik u blizini provodnika signalnih ili data kola, unutar njih mogu se generisati indukovani naponi. Rezultat je pojava šuma i struja petlji.

Brzi električni tranzijenti imaju vrlo malu energiju, ali mogu da ometaju rad kola IT uređaja.

\section{Generisanje brzih tranzijenata}

Kada se isključi električno kolo kroz koje teče struja (slika 3) ona se trenutno prekine. $U$ momentu prekidanja

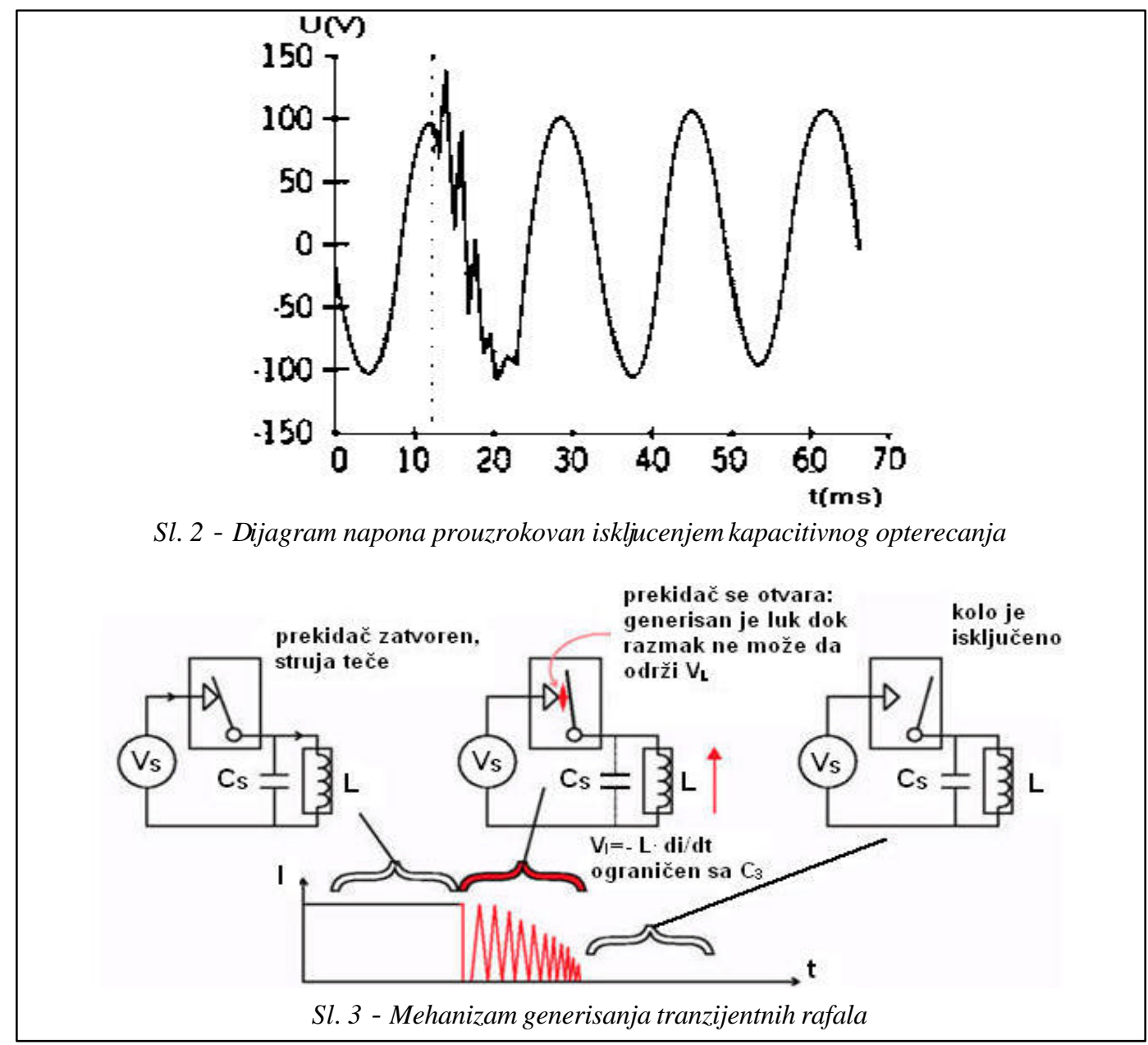


struje dolazi do promene struje di/dt. Sva električna kola imaju neku rasipnu induktivnost pridruženu ožičenju, a neki tipovi opterećenja, kao što su motori i solenoidi, imaju veću induktivnost.

Napon na induktivnosti L, nastao usled promene struje, određen je prema izrazu:

$u=-L \cdot d i / d t$

Ako je di/dt beskonačno veliko, onda ta pojava uzrokuje beskonačno visoki napon. Naravno, to se ne dešava u praksi, pa je brzina porasta napona ograničena parazitnom i sopstvenom kapacitivnošću kola. Tada se na otvorenim kontaktima prekidača pojavljuje visoka trenutna vrednost napona, superponirana sa radnim naponom električ nog kola. To izaziva proboj tankog vazdušnog razmaka između otvorenih kontakata prekidača i struja ponovo poteče, izazivajući naglo smanjenje vršnih vrednosti napona, tako da se prekine kratkotrajno varničenje. Ovaj ponovni prekid struje izaziva nove naponske impulse koji izazivaju sledeće varničenje. Proces se sam po sebi ponavlja sve dok se ne uspostavi dovoljno veliki razmak između kontakata da napon na njima ne izaziva proboj. Tada je električno kolo stvarno prekinuto. Vidljivi efekat je kratkotrajno varničenje između kontakata koje se, u stvari, sastoji od čitave serije mikrovarničenja, čija amplituda i brzina ponavljanja zavise od karakteristika prekidača i električnog kola (rafali).

Pri svakoj pojavi varničenja generišu se napon $u(t)$ i struja $i(t)$, istovremeno duž ožičenja električ nog kola.
Iako se ova pojava dešava u mrežnom kolu, rafali šuma javljaju se i na drugim tačkama vezanim s distributivnom mrežom. Impulsi su veoma brzi (reda nanosekundi) i sprežu se i na druga ožičenja u blizini električnog kola. Amplitude napona, koji se javljaju na ovako spregnutim kolima, obično su reda nekoliko stotina volti, a povremeno i nekoliko hiljada volti.

\section{Karakteristike tranzijentnih rafala}

Pojava tranzijentnih rafala, sa gledišta ugrožene opreme koja nije povezana sa izvorom smetnji, obično je slučajna, mada se neki slučajevi automatskih prekidanja mogu pojaviti u pravilnim intervalima. Šum od elektromotora sa četkicama i od elektrolučnog zavarivanja su posebni slučajevi ovakvog mehanizma generisanja i obično imaju strogo periodičan karakter.

Amplituda tranzijentnih rafala naglo opada sa rastojanjem usled gubitaka na prenosnoj liniji, u zavisnosti od karakeristika ožičenja, tako da su značajni samo izvori smetnji udaljeni nekoliko metara od ugrožene opreme. Oblici tranzijentnih impulsa takođe su slučajni, mada su istraživanja pokazala da je frekvencija ponavljanja u opsegu od $100 \mathrm{kHz}$ do 1 $\mathrm{MHz}$, a brzina uspostavljanja naponskog impulsa (du/dt - strmina čela impulsa) približno je proporcionalna kvadratnom korenu amplitude.

\section{Uticaj na elektronsku opremu}

Retko se dešava, ali nije nemoguće, da tranzijenti preko induktivne sprege ostvare spregu sa ugroženom opremom u blizini. Međutim, tranzijenti uglavnom 
prodiru u opremu preko kablovskih veza. $\mathrm{Na}$ signalnim ulazima (portovima) impulsi su najčešće nepromenljivi u zajedničkom modu, $\mathrm{tj}$. na sve provodnike (ili na ekran-širm) pri istoj amplitudi u odnosu na spoljno uzemljenje.

Na mrežnom priključku (portu) tranzijenti se mogu pojaviti ilili u zajedničkom modu i/ili u diferencijalnom modu između faza. Zajednički mod sprezanja uključuje i uzemljeni zaštitni provodnik.

Slabo filtriranje ili neadekvatni završeci ekrana (uzemljenog plašta) na svakoj unutrašnjoj vezi dopuštaju prolaz tranzijenata u elektronska kola, gde se oni pojavljuju na osetljivim čvorovima kao ometajući signali.

S obzirom na tendenciju da digitalna kola, pri normalnom radu, budu što osetljivija, svaki kratki impuls, kao i kod drugih vrsta tranzijenata, može se registrovati kao validni signal. U slučaju brzih tranzijenata postoji veća verovatnoća da se to desi, jer se jedan od mnoštva impulsa može podudariti sa kritičnom vremenskom bazom. Naravno, i analogna kola takođe mogu biti osetljiva na brze tranzijente. Tipičan slučaj je pojava zasićenja kod osetljivih pojačavača.

Kola brojača impulsa takođe su osetljiva ako se rafali impulsa maskiraju kao realni ulaz.

\section{Standardizacija pojave}

Standard IEC 61000-4-4 (i njegov EN ekvivalent) u principu je osnovni standard za ispitivanje imunosti na brze tranzijente. On primenjuje standardizovane oblike rafala preko definisane mre- že za sprezanje (,kuplovanje“) na mrežno napajanje ispitivane opreme i preko definisanog uređaja za kapacitivnu spregu na bilo koje priključke ispitivane opreme za prenos signala. Koristi se isključivo konduktivno sprezanje i nema specifikacije za imunost na indukovane tranzijentne poremećaje.

Izbor priključaka ispitivane opreme na koje će se primeniti rafali naponskih impulsa zavisi od zahteva (instrukcija) standarda za poje dinačni proizvod koji će se ispitivati, ali se u opštem slučaju primenjuju na AC i DC priključcima za napajanje, na priključcima za prenos signala i na priključcima za upravljanje (kontrolu) ukoliko mogu biti povezani kablovima dužim od $3 \mathrm{~m}$.

Na slici 4 prikazan je primer primene ispitnih naponskih impulsa direktnim sprezanjem sa priključcima mrežnog napajanja ispitivane opreme.

Radi standardizovanja ispitivanja moraju se definisati oblik impulsa, amplituda, broj impulsa, njihova frekvencija i dužina „rafala“, kao i frekvencija ponavljanja.

Zahtevana unutrašnja impedansa generatora naponskih impulsa je $50 \Omega$, a oblik impulsa je kalibrisan za opterećenje od $50 \Omega$. Očekuje se i novi amandman standarda, gde bi se to definisalo i za impedansu od $1000 \Omega$.

Impedansa opterećenja predstavljena opremom koja se ispitije (EUT) nepoznata je i može se kretati od kratkog spoja do otvorenog kola, tako da je stvarni ispitni napon između priključka ispitivane opreme i zemlje (uzemljene ploče) praktično nepredvidiv. 


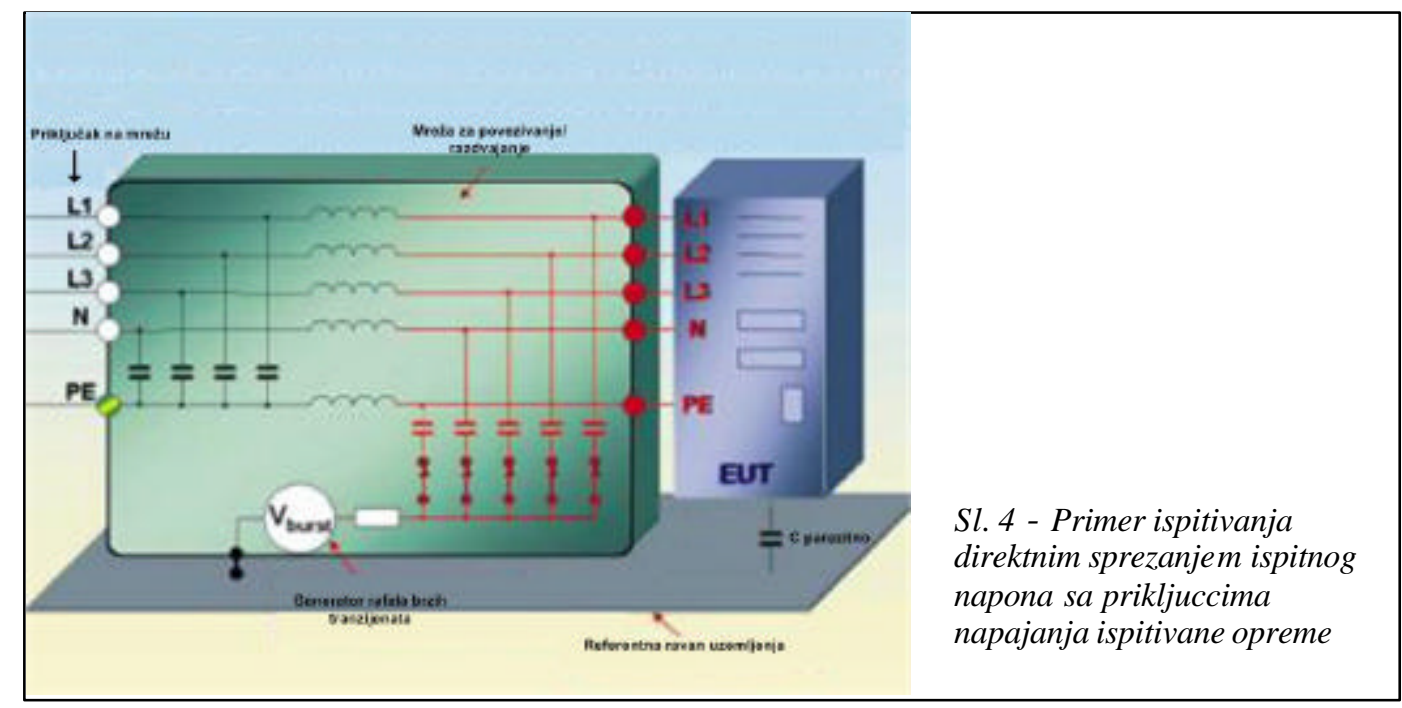

Novi amandman standarda treba da obezbedi da oblik rafala impulsa bude nepromenljiv za različite generatore $\mathrm{i}$ različitu opremu koja se ispituje.

Definicije oblika impulsa brzih tranzijenata prikazani su na slici 5 .

\section{Primena brzih tranzijenata}

Brzi tranzijenti (rafali naponskih impulsa) primenjuju se na priključke (portove) napajanja ispitivane opreme preko sprežuće - rasprežuće mreže (couipling - decouipling network, CDN), a drugi portovi - priključci (signalni, telekomunikacioni i upravljački portovi) preko uređaja za kapacitivno sprezanje (capacitive couipling clamp). Za ispitni napon referentna je uzemljena tačka na ispitnom generatoru.

Osnovni standard ne definiše dovoljno jasno kako treba primeniti rafale impulsa na mrežno napajanje ispitivane opreme preko CDN, već prikazuje separatnu primenu na fazne provodnike, nulti i zaštitni provodnik (differential mode).
Neki standardi za pojedinačne proizvode, pozivajući se na osnovni standard, definišu ovo ispitivanje na „opšti način“ (common mode), tj. primenjuju rafale impulsa na sve tri linije simultano.

U praksi, izbor je stvar tumačenja standarda, a i jedno i drugo tumačenje moglo bi biti opravdano. Ako se ispitivanje koristi za proveru imunosti proizvoda u realnim uslovima, onda je najbolje primeniti diferencijalni način sprezanja (jedan po jedan - linija prema zemlji), a ako treba striktno poštovati standard pojedinačnog proizvoda onda i ograničeno tumačenje može biti razumno. Primena brzih tranzijenata preko uređaja za kapacitivno sprezanje vrši se isključivo na opšti način (common mode).

Pri ispitivanju imunosti na brze tranzijente treba voditi računa da se radi o visokim frekvencijama - spektar frekvencija do $100 \mathrm{MHz}$, pa je neophodna primena uzemljene referentne ploče (GRP). Ukoliko se ne bi koristilo referentno uzemljenje ne bi se mogla obezbediti ponovljivost ispitivanja i provera usaglašenosti. 


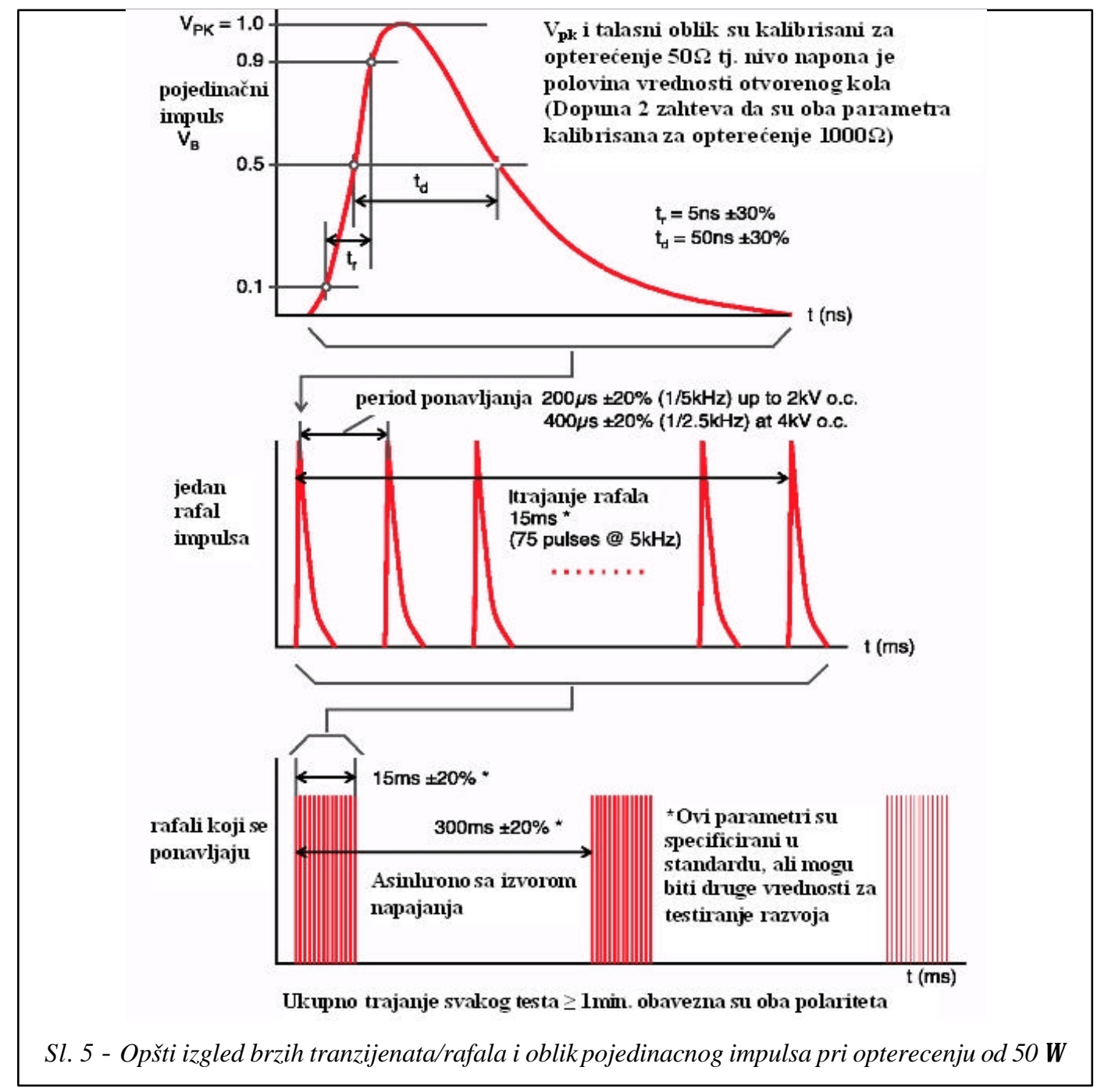

Da bi se izbegle nepoželjne impedanse, neophodna su sledeća ograničenja:

- ispitivana oprema treba da bude $10 \mathrm{~cm}$ iznad uzemljene ploče (za stone uređaje $80 \mathrm{~cm}$ iznad poda);

- uzemljena ploča treba da je sa svih strana za najmanje $10 \mathrm{~cm}$ većih dimenzija od ispitivane opreme;

- ispitivana oprema i uređaj za kapacitivno sprezanje treba da je najmanje 0,5 m udaljen, od drugih provodnih struktura, uključujući ispitni generator i zidove prostorije;

- dužina kabla između sprežnih uređaja (clamp i CDN) i ispitivane opreme mora biti $1 \mathrm{~m}$ ili manja (najbolje je koristiti standardizovani ispitni kabl od $1 \mathrm{~m}$ za svu ispitivanu opremu);

- ispitni generator mora biti povezan sa uzemljenom pločom (GRP) preko veze niske iduktivnosti, što treba primeniti i za uređaj za kapacitiv no sprezanje. 
Ove zahteve treba ispuniti sve zajedno, jer u slučaju odstupanja javljaju se nepoželjne induktivnosti i kapacitivnosti u sprežnom kolu i mogu uzrokovati varijacije primenjenog ispitnog napona.

Neke od ovih zahteva standarda neće biti lako ispuniti i takvi slučajevi će zahtevati domišljatost i pažljivo sagledavanje.

Osnovni standard zahteva da se ispitivana oprema izlaže rafalima naponskih impulsa najmanje 1 minut za svaki polaritet, a neki standardi za pojedinačne proizvode, na primer, do 2 minuta.

Osnovno je da se ispitivana oprema izlaže rafalima naponskih impulsa dovoljno dugo da se istraži bilo koji slučaj osetljivosti ispitivane opreme na iste.

\section{Rezultati ispitivanja}

Ispitivanje imunosti elektronske opreme na brze tranzijente izvršeno je na printeru sa fiskalnom memorijom.

Ispitivanje je izvršeno u skladu sa standardom EN 61000-4-4, generatorom brzih tranzijenata amplitude $1 \mathrm{kV}$, nepre- kidno $30 \mathrm{~s}$ sa frekvencijom ponavljanja impulsa $5 \mathrm{kHz}$. Izgled naponskih impulsa prikazan je na slici 6 .

U toku ispitivanja nisu zapaženi negativni uticaji rafala brzih tranzijenata na rad printera. Radne funkcije printera ostale su nepromenjene, a nije zapažena ni promena u sadržaju fiskalne memorije printera.

\section{Zaključak}

Izvori tranzijentnih poremećaja (izuzev elektrostatičkih), obično nisu u blizini ugrožene računarske i elektronske opreme i njihova energija se najčešće prenosi u elektronska kola preko kablovskih veza. Stoga, ispitivanje imunosti obuhvata primenu višestrukih naponskih impulsa definisanog oblika i nivoa na svaki relevantni kablovski priključak, na specificiran i ponovljiv način.

U svetu je prisutan trend porasta zahteva za ispitivanje imunosti uređaja na uticaje tranzijentnih poremećaja $u$ mreži za napajanje. Ova ispitivanja imaju primenu pri ispitivanju širokog spektra

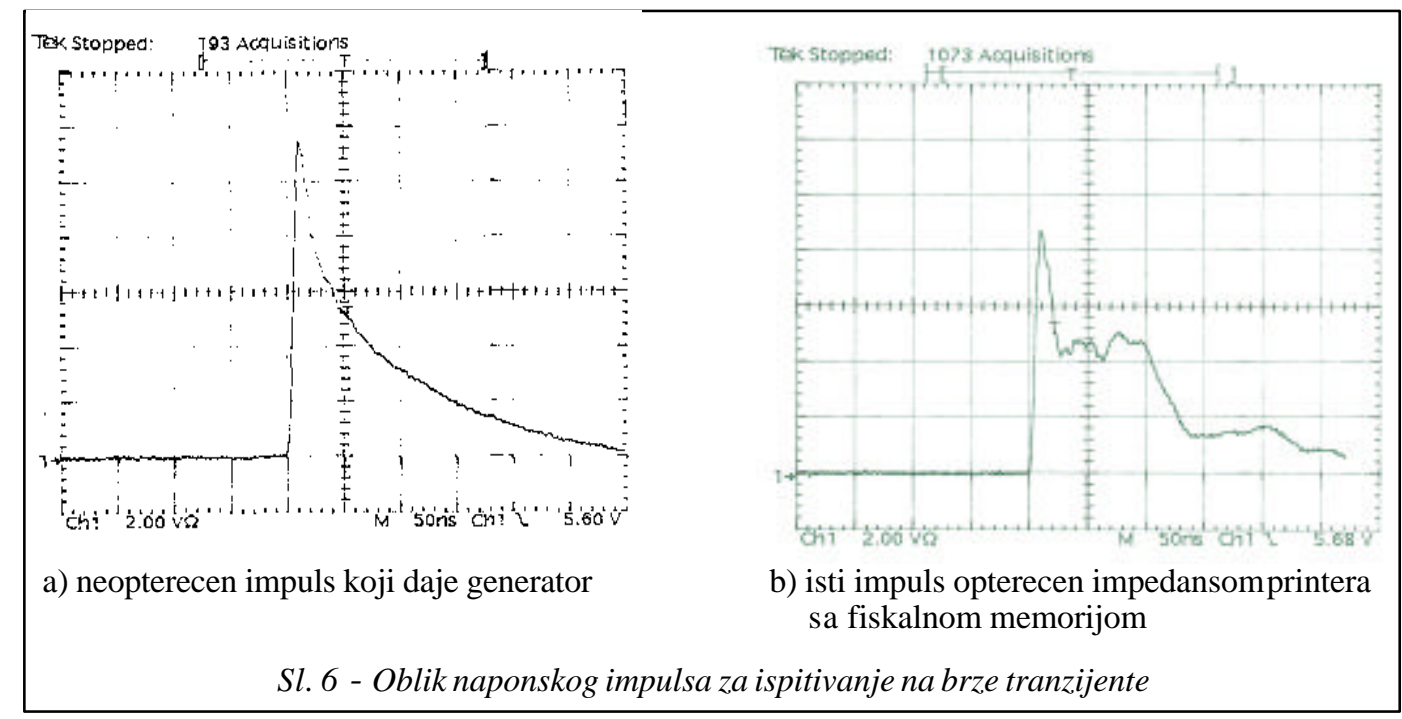


proizvoda, kao što su uredaji informatičke tehnologije, telekomunikacioni uređaji, komercijalni i industrijski proizvodi, motorna vozila i njihove komponente.

$\mathrm{S}$ obzirom na to da se radi o veoma kompleksnoj oblasti, pre svega zbog pojava visokonaponskih impulsa ekstremno kratkog trajanja, uz veliku strminu čela i visoku frekvenciju ponavljanja, nejasnoće $\mathrm{u}$ zahtevima, nedovoljno iskustva u postavljanju ispitivanja, nedovoljno poznavanje pojava, ispitivane opreme $\mathrm{i}$ ispitne opreme može izazvati oštećenja i jedne i druge opreme, kao nemogućnost tumačenja rezultata ispitivanja i ocenjivanja.
Očigledno je da ova ispitivanja nisu rutinska, pa se u mnogim stručnim člancima iz ove oblasti i potencira stručnost $i$ iskustvo ispitivača.

Literatura:

[1] Schaffner, Transient Immunity Testing a handy guide Schaffner, www. Schaffner.com

[2] IEC 61000-4-4 (2001), Electromagnetic compatibility (EMC) - Part 4-4: Testing and measurement techniques IEC (EN) 61000-4-4 Electrical fast transient/burst immunity test, International Electrotechnical Commission.

[3] John De Dad (2006), Looking For Sources of Transient Overvoltages, www.ecmweb.com

[4] JUS IEC 50 (1997), Medunarodni elektrotehnicki recnik Poglavlje 161: Elektromagnetska kompatibilnost, JSZ.

[5] Keth Armstrong, EMC Testing Part 3- Fast transient Burst, Surge, Electrostaic Discharge (http://64.70.157.146/ archive) 